\title{
Early stimulated thyroglobulin for response prediction after recombinant human thyrotropin-aided radioiodine therapy
}

\author{
Hee Jeong Park ${ }^{1} \cdot$ Jung-Joon Min ${ }^{1} \cdot$ Hee-Seung Bom ${ }^{1} \cdot$ Jahae Kim $^{2}$ • \\ Ho-Chun Song ${ }^{2} \cdot$ Seong Young Kwon ${ }^{1}$ (D)
}

Received: 18 April 2017/ Accepted: 2 July 2017/Published online: 7 July 2017

(c) The Author(s) 2017. This article is an open access publication

\begin{abstract}
Objective Measurement of recombinant human thyrotropin (rhTSH)-stimulated thyroglobulin (Tg) is generally recommended $72 \mathrm{~h}$ after the second rhTSH injection. However, due to the acute effect of I-131 on thyrocytes, $\mathrm{Tg}$ measured after radioiodine therapy (RIT) would not accurately reflect the thyroid tissue burden. We aimed to determine predictive values of serum $\mathrm{Tg}$ level measured just before rhTSH-aided RIT and to compare the results obtained just after RIT in patients with differentiated thyroid carcinoma (DTC).

Methods We evaluated 150 patients with DTC who underwent rhTSH-aided RIT (2.96-6.66 GBq) after total thyroidectomy between 2009 and 2014. Serum Tg level was measured $24 \mathrm{~h}$ (early Tg) and 72 (or 96) h (delayed $\mathrm{Tg}$ ) after the second rhTSH injection. An excellent response was defined based on the latest American Thyroid Association Guidelines. Univariate and multivariate analyses were performed for early $\mathrm{Tg}$, delayed $\mathrm{Tg}$, and other clinical variables.

Results In the multivariate analysis, tumor size [odds ratio (OR) 1.716; 95\% confidence interval (CI) 1.019-2.882; $p=0.042$ ] and early $\mathrm{Tg}$ level (OR 2.012; 95\% CI $1.384-2.925, p<0.001)$ independently predicted excellent responses. The cutoff for the best early $\mathrm{Tg}$ level to predict a
\end{abstract}

Seong Young Kwon

suninocean@gmail.com

1 Department of Nuclear Medicine, Chonnam National University Hwasun Hospital, 322 Seoyang-ro, Hwasun-eup, Hwasun-Gun, Jeonnam 58128, South Korea

2 Department of Nuclear Medicine, Chonnam National University Hospital, 42 Jebong-ro, Donggu, Gwangju 61469, South Korea non-excellent response was $2.0 \mathrm{ng} / \mathrm{mL}$. Delayed $\mathrm{Tg}$ was not a significant predictor (OR 0.992; 95\% CI 0.969-1.015; $p=0.492)$.

Conclusions Early stimulated $\mathrm{Tg}$ significantly predicted therapeutic response after rhTSH-aided RIT in patients with DTC. Therefore, serum Tg should be measured before RIT to predict therapeutic responses.

Keywords Differentiated thyroid carcinoma $\cdot$ Radioiodine therapy · Recombinant human thyrotropin · Thyroglobulin . Therapeutic response

\section{Introduction}

Total thyroidectomy followed by radioiodine therapy (RIT) is the treatment of choice for differentiated thyroid carcinoma (DTC) $[1,2]$. Although DTC shows a relatively good response to RIT, unsuccessful ablation is reported in about $6-30 \%$ of patients [3-8], so additional treatments, such as surgical procedures or repeated RIT, and life-long followup are required. Serum thyroglobulin (Tg) levels measured during hypothyroidism, just before RIT, have good prognostic values for predicting successful ablation [9-12].

Recombinant human thyrotropin (rhTSH) represents a safe and effective means of increasing serum TSH in preparation for RIT, avoiding signs and symptoms of hypothyroidism associated with thyroid hormone withdrawal (THW) [13, 14]. I-131 is usually administered on the day after the 2nd injection of rhTSH according to the conventional schedule $[5,6]$. On the other hand, serum $\mathrm{Tg}$ should be measured $72 \mathrm{~h}$ after final injection of rhTSH, because this day corresponds to the peak serum Tg levels $[15,16]$. However, due to the radioiodine-induced damage to normal thyroid cells and release of stored $\mathrm{Tg}$ in thyroid 
follicles, the Tg level measured after RIT would not be reliably predictive $[17,18]$.

The present study was undertaken to determine the value of $\mathrm{Tg}$ measured before and after RIT that predicts a therapeutic response in DTC patients with rhTSH-aided RIT.

\section{Materials and methods}

\section{Subjects}

Between August 2009 and May 2014, 430 DTC patients, who underwent total or near-total thyroidectomy followed by rhTSH-aided RIT in our institution, were initially analyzed. Among these patients, patients with high levels of serum anti-Tg autoantibodies (TgAbs) more than $100 \mathrm{IU} /$ $\mathrm{mL}(n=37)$, repeated RIT $(n=27)$, missing Tg measurements $(n=109)$, distant metastases $(n=8)$, and insufficient follow-up $(n=99)$ were excluded. Finally, 150 patients were enrolled in this study. This retrospective study was performed in accordance with the ethical standards laid down in the 1964 Declaration of Helsinki and its later amendments, and ethical approval was obtained from the local ethics committee (CNUHH-2016-069). For this type of study, informed consent was waived.

\section{Radioiodine therapy}

Patients were referred for RIT 0-27 months (mean 4.0 months) after surgery. All patients had received 2 consecutive daily doses of $0.9 \mathrm{mg}$ rhTSH (Thyrogen, Genzyme Transgenics Corp., Cambridge, USA) administered by the intramuscular route prior to RIT. According to the instructions regarding limiting exposure to environmental iodine, patients consumed a low-iodine diet for 2 weeks prior to RIT. Twenty-four hours after the 2 nd injection of rhTSH, a therapeutic dose of I-131 (2.96-6.66 GBq) was administered. An I-131 whole body scan was performed 7-8 days after oral ingestion of I-131.

\section{Tg and TSH measurement}

For serum Tg measurements, blood samples were collected two times: before RIT ( $24 \mathrm{~h}$ after the 2 nd rhTSH injection) (early $\mathrm{Tg}$ ) and after RIT (72 or $96 \mathrm{~h}$ after the 2nd rhTSH injection) (delayed $\mathrm{Tg}$ ). Serum $\mathrm{Tg}$ was measured by an immunoradiometric assay (IRMA) (RIA Tg-plus, BRAHMS GmbH, Hennigsdorf, Germany) with an analytical sensitivity (AS) and functional sensitivity (FS) of 0.08 and $0.2 \mathrm{ng} / \mathrm{mL}$, respectively. Serum TgAbs was measured by a radioimmunoassay method (RIA anti-Tgn, BRAHMS GmbH, Hennigsdorf, Germany) with an AS of $5.5 \mathrm{U} / \mathrm{mL}$ and FS of $<20 \mathrm{U} / \mathrm{mL}$. Serum TSH levels were determined by IRMA (TSH-CTK-3, DiaSorin, Saluggia, Italy) with an AS and FS of 0.04 and $0.07 \mathrm{mU} / \mathrm{L}$, respectively. The cut-off point for TSH, above which corresponding stimulated $\mathrm{Tg}$ levels were acceptable, was $30 \mathrm{mU} / \mathrm{L}$.

\section{Follow-up examination}

The first post-ablation follow-up examination was performed 6-12 months (mean 9.0 months) after RIT. The follow-up protocol included neck ultrasound (US) and serum Tg measurement. Suppressed Tg was measured in 60 patients, and the remainder of the patients $(n=90)$ underwent diagnostic I-123 whole body scan (DxWBS) with stimulated $\mathrm{Tg}$ aided by rhTSH or endogenous TSH.

Definitions of therapeutic responses followed the 2015 American Thyroid Association Guidelines [19]: (1) excellent response-negative imaging and either suppressed $\mathrm{Tg}$ $<0.2 \mathrm{ng} / \mathrm{mL}$ or TSH-stimulated $\mathrm{Tg}<1 \mathrm{ng} / \mathrm{mL}$; (2) biochemical incomplete response-negative imaging and suppressed $\mathrm{Tg} \geq 1 \mathrm{ng} / \mathrm{mL}$ or stimulated $\mathrm{Tg} \geq 10 \mathrm{ng} / \mathrm{mL}$; (3) structural incomplete response-structural or functional evidence of disease with any $\mathrm{Tg}$ level with or without TgAbs; (4) indeterminate response-nonspecific findings on imaging studies or suppressed Tg detectable but $<1 \mathrm{ng} /$ $\mathrm{mL}$ or stimulated $\mathrm{Tg}$ detectable but $<10 \mathrm{ng} / \mathrm{mL}$. We classified patients into 2 groups: the excellent response group and the non-excellent response group (which included those showing a biochemical incomplete response, structural incomplete response, and indeterminate response).

\section{Statistical analysis}

Using a logistic regression analysis, clinicopathologic variables were tested for their association with an excellent response using a univariate analysis: early $\mathrm{Tg}$, delayed $\mathrm{Tg}$, other clinical (age at diagnosis, sex, I-131 dose), and pathologic markers [American Joint Cancer Committee (AJCC)/International Union Against Cancer (UICC) TNM staging ( 7 th edition), presence of extra-thyroid extension, tumor size, multicentricity, and bilaterality]. Variables with $p$ value $\leq 0.20$ were further analyzed by a multivariate logistic regression analysis using the stepwise backward method [20, 21]. A $p$ value $<0.05$ was considered statistically significant. A receiver-operating characteristic (ROC) curve analysis was used to define the best cut-off value for serum Tg at ablation. For the established cut-off value, we calculated the sensitivity, specificity, positive predictive value (PPV), negative predictive value (NPV), and area under the curve (AUC). Statistical analysis was performed using SPSS version 21.0 for Windows ${ }^{\circledR}$ (IBM Corp., Armonk, USA). 


\section{Results}

Patients' characteristics are summarized in Table 1. The study population comprised 114 women $(76.0 \%)$ and 36 men $(24.0 \%$ ), aged $20-79$ years (mean 48.8 ) at the time of surgery. The histological DTC subtype was papillary in 148 cases $(98.7 \%)$ and follicular in 2 cases $(1.3 \%)$. At the time of RIT, early $\mathrm{Tg}$ ranged from 0.1 to $117.9 \mathrm{ng} / \mathrm{mL}$

Table 1 Patients' characteristics

\begin{tabular}{|c|c|}
\hline Parameter & No. of patients (\%) \\
\hline Age (years) & $48.8 \pm 11.8($ range $20-79)$ \\
\hline \multicolumn{2}{|l|}{ Sex } \\
\hline Male & $36(24.0 \%)$ \\
\hline Female & $114(76.0 \%)$ \\
\hline \multicolumn{2}{|l|}{ T stage } \\
\hline $\mathrm{T} 1$ & $85(56.7 \%)$ \\
\hline $\mathrm{T} 2$ & $6(4.0 \%)$ \\
\hline $\mathrm{T} 3$ & $48(32.0 \%)$ \\
\hline $\mathrm{T} 4$ & $11(7.3 \%)$ \\
\hline \multicolumn{2}{|l|}{$\mathrm{N}$ stage } \\
\hline $\mathrm{N} 0 / \mathrm{Nx}$ & $29(19.3 \%)$ \\
\hline N1a & $95(63.3 \%)$ \\
\hline N1b & $26(17.3 \%)$ \\
\hline Tumor size $(\mathrm{cm})$ & $1.1 \pm 0.7($ range $0.3-5.0)$ \\
\hline \multicolumn{2}{|l|}{ Multiplicity } \\
\hline No & $69(46.0 \%)$ \\
\hline Yes & $81(54.0 \%)$ \\
\hline \multicolumn{2}{|l|}{ Bilaterality } \\
\hline No & $90(60.0 \%)$ \\
\hline Yes & $60(40.0 \%)$ \\
\hline \multicolumn{2}{|l|}{ Extrathyroidal extension } \\
\hline No & $91(60.7 \%)$ \\
\hline Yes & $59(39.3 \%)$ \\
\hline \multicolumn{2}{|l|}{ Tumor pathology } \\
\hline Papillary & $148(98.7 \%)$ \\
\hline Follicular & $2(1.3 \%)$ \\
\hline \multicolumn{2}{|c|}{ Dose of administered I-131 (GBq) } \\
\hline 2.96 & $18(12.0 \%)$ \\
\hline 3.70 & $87(58.0 \%)$ \\
\hline 5.55 & $9(6.0 \%)$ \\
\hline 6.66 & $36(24.0 \%)$ \\
\hline Early Tg (ng/mL) & $3.2 \pm 11.4$ (range $0.1-117.9)$ \\
\hline Delayed Tg (ng/mL) & $9.6 \pm 27.1$ (range $0.1-198.7$ ) \\
\hline Early TSH (mU/L) & $94.9 \pm 23.7($ range $46.4-166.9)$ \\
\hline Delayed TSH (mU/L) & $31.4 \pm 27.5($ range $2.8-80.5)$ \\
\hline
\end{tabular}

Early $\mathrm{Tg}$ and early $\mathrm{TSH}$ serum $\mathrm{Tg}$ and $\mathrm{TSH}$ measured just before radioiodine therapy, delayed $\mathrm{Tg}$ and delayed $\mathrm{TSH}$ serum $\mathrm{Tg}$ and TSH measured after radioiodine therapy, $T g$ thyroglobulin, TSH thyrotropin (mean 3.2) and delayed Tg ranged from 0.1 to $198.7 \mathrm{ng} / \mathrm{mL}$ (mean 9.6).

At the follow-up examination, an excellent response was observed in $85(56.7 \%)$ patients. In the $65(43.3 \%)$ patients with non-excellent responses, $10(6.7 \%)$ patients had a biochemical incomplete response, $10(6.7 \%)$ had a structural incomplete response, and $45(30.0 \%)$ had an indeterminate responses.

Variables significantly associated with an excellent response in the univariate analysis are reported in Table 2. Older age $(p=0.041)$, smaller tumors $(p=0.009)$, and low level of early $\operatorname{Tg}(p<0.001)$ significantly predicted an excellent response. In the multivariate logistic regression analysis, early $\mathrm{Tg}$ [odds ratio (OR) $2.012 ; 95 \%$ confidence interval (CI) $1.384-2.925 ; p<0.001]$ and tumor size (OR $1.714 ; 95 \%$ CI $1.019-2.882 ; p=0.042$ ) significantly predicted an excellent response (Table 3). However, delayed $\mathrm{Tg}$ did not show statistical significance for response prediction after RIT (OR 0.992; 95\% CI 0.969-1.015; $p=0.492$ ).

An ROC curve analysis showed that the optimal cut-off value for early $\mathrm{Tg}$ was $2.0 \mathrm{ng} / \mathrm{mL}$; it had a sensitivity of $46.2 \%$, specificity of $95.3 \%$, PPV of $88.2 \%$, and NPV of $69.8 \%$ for predicting a non-excellent response (AUC 0.704; $p<0.001$ ) (Fig. 1). In 116 patients with an early Tg level $\leq 2.0 \mathrm{ng} / \mathrm{mL}$, an excellent response was observed in 81 patients $(69.8 \%)$, whereas only $4 / 34(11.8 \%)$ patients with early Tg levels $>2.0 \mathrm{ng} / \mathrm{mL}$ showed an excellent response (Table 4).

\section{Discussion}

In patients with DTC, the stimulated Tg level measured just before RIT proved to be a biochemical tumor marker that could predict persistent or recurrent disease after THW [9-12]. In a recent meta-analysis involving 3947 patients across a broad spectrum of disease, it was demonstrated that the pre-ablation Tg level could be a useful negative predictor of persistent or recurrent DTC. The overall NPV was $94 \%$ when the pre-ablation $\mathrm{Tg}$ level was $<10 \mathrm{ng} / \mathrm{mL}$ [12]. In addition, the stimulated $\mathrm{Tg}$ measured after THW could be used to predict the volume of the thyroid remnants or the residual tumor burden [22]. However, there is no consensus available with respect to the clinical implications or testing protocol for stimulated Tg at rhTSH-aided RIT, although rhTSH is now widely used as a method for RIT preparation.

From the previous studies, serum $\mathrm{Tg}$ should be measured in the 3 days after the 2nd injection of rhTSH $[15,16]$. In 1998, Genzyme showed the serial Tg data that resulted in FDA approval. In that study protocol, $24 \mathrm{~h}$ after 
Table 2 Results of the univariate analysis of therapeutic response predictionrelated parameters

\begin{tabular}{|c|c|c|c|}
\hline Parameters & Excellent response, $n(\%)$ & Non-excellent response, $n(\%)$ & $p$ value \\
\hline \multicolumn{4}{|l|}{ Age (years) } \\
\hline$<45$ years & $24(45.3 \%)$ & $29(54.7 \%)$ & \multirow[t]{2}{*}{$0.041 *$} \\
\hline$\geq 45$ years & $61(62.9 \%)$ & $36(37.1 \%)$ & \\
\hline \multicolumn{4}{|l|}{ Sex } \\
\hline Male & $18(50.0 \%)$ & $18(50.0 \%)$ & \multirow[t]{2}{*}{0.441} \\
\hline Female & $67(58.8 \%)$ & $47(41.2 \%)$ & \\
\hline \multicolumn{4}{|l|}{ T stage } \\
\hline $\mathrm{T} 1$ & $52(61.2 \%)$ & $33(38.8 \%)$ & \multirow[t]{4}{*}{0.274} \\
\hline $\mathrm{T} 2$ & $2(33.3 \%)$ & $4(66.7 \%)$ & \\
\hline $\mathrm{T} 3$ & $27(56.3 \%)$ & $21(43.8 \%)$ & \\
\hline $\mathrm{T} 4$ & $4(36.4 \%)$ & $7(63.6 \%)$ & \\
\hline \multicolumn{4}{|l|}{$\mathrm{N}$ stage } \\
\hline $\mathrm{N} 0 / \mathrm{Nx}$ & $19(65.5 \%)$ & $10(34.5 \%)$ & \multirow[t]{3}{*}{0.205} \\
\hline N1a & $55(57.9 \%)$ & $40(42.1 \%)$ & \\
\hline N1b & $11(42.3 \%)$ & $15(57.7 \%)$ & \\
\hline Tumor size $(\mathrm{cm})$ & $1.0 \pm 0.6$ & $1.3 \pm 0.9$ & $0.009 *$ \\
\hline \multicolumn{4}{|l|}{ Multiplicity } \\
\hline No & $37(53.6 \%)$ & $32(46.4 \%)$ & \multirow[t]{2}{*}{0.512} \\
\hline Yes & $48(59.3 \%)$ & $33(40.7 \%)$ & \\
\hline \multicolumn{4}{|l|}{ Bilaterality } \\
\hline No & $48(53.3 \%)$ & $42(46.7 \%)$ & \multirow[t]{2}{*}{0.401} \\
\hline Yes & $37(61.7 \%)$ & $23(38.3 \%)$ & \\
\hline \multicolumn{4}{|c|}{ Extrathyroidal extension } \\
\hline No & $54(59.3 \%)$ & $37(40.7 \%)$ & \multirow[t]{2}{*}{0.500} \\
\hline Yes & $31(52.5 \%)$ & $28(47.5 \%)$ & \\
\hline \multicolumn{4}{|c|}{ Dose of administered I-131 (GBq) } \\
\hline 2.96 & $13(72.2 \%)$ & $5(27.8 \%)$ & \multirow[t]{4}{*}{0.412} \\
\hline 3.70 & $48(55.2 \%)$ & $39(44.8 \%)$ & \\
\hline 5.55 & $6(66.7 \%)$ & $3(33.3 \%)$ & \\
\hline 6.66 & $18(50.0 \%)$ & $18(50.0 \%)$ & \\
\hline Early Tg (ng/mL) & $0.8 \pm 0.8$ & $6.4 \pm 16.8$ & $<0.001 *$ \\
\hline Delayed Tg (ng/mL) & $5.3 \pm 16.2$ & $14.9 \pm 36.0$ & $0.074^{\dagger}$ \\
\hline
\end{tabular}

$T g$ thyroglobulin

* Statistically significant $(p<0.05)$

${ }^{\dagger}$ Statistical trend $(0.05 \leq p \leq 0.20)$
Table 3 Results of the multivariate analysis of therapeutic response prediction-related parameters

\begin{tabular}{lcc}
\hline Parameter & Odds ratio $(95 \% \mathrm{CI})$ & $p$ value \\
\hline Age (years) & $0.450(0.202-0.999)$ & 0.050 \\
Tumor size $(\mathrm{cm})$ & $1.714(1.019-2.882)$ & $0.042^{*}$ \\
Early Tg $(\mathrm{ng} / \mathrm{mL})$ & $2.012(1.384-2.925)$ & $<0.001 *$ \\
Delayed Tg $(\mathrm{ng} / \mathrm{mL})$ & $0.992(0.969-1.015)$ & 0.492 \\
\hline
\end{tabular}

$C I$ confidence interval, $T g$ thyroglobulin

* Statistically significant $(p<0.05)$ the 2nd rhTSH injection, $148 \mathrm{MBq}$ radioiodine were administered orally and $\mathrm{Tg}$ levels were measured on days $1,2,3$, and 7 . They found that maximum serum Tg levels were observed on day 3 in most patients. However, the administered dose of radioiodine was not a therapeutic dose that could cause acute thyroid injury [16]. This timing of $\mathrm{Tg}$ measurement has raised concerns about its reliability as a tumor marker, because acute thyroid injuries would contribute to $\mathrm{Tg}$ production. Taieb et al. [17] showed sequential elevation of median serum $\mathrm{Tg}$ levels during the $48 \mathrm{~h}$ after I-131 administration (3.7 GBq) in DTC patients with hypothyroidism. $\mathrm{Tg}$ levels increased due to an acute effect of I-131 on $\mathrm{Tg}$ release. Furthermore, the $\mathrm{Tg}$ 


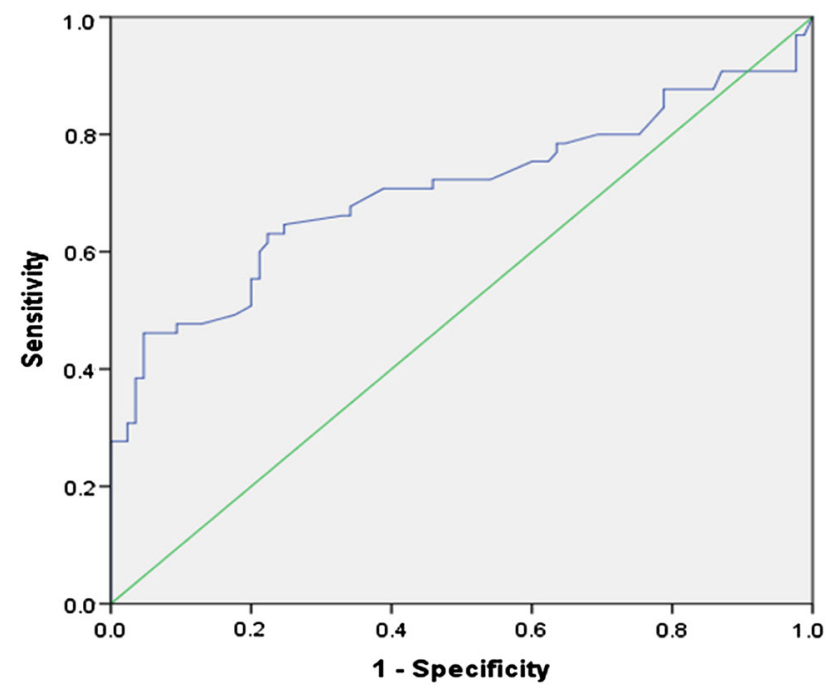

Fig. 1 Results of the receiver-operating characteristic (ROC) curve analysis for the early thyroglobulin levels that predict non-excellent responses after rhTSH-aided radioiodine therapy

increments at $48 \mathrm{~h}$ were not correlated with $\mathrm{Tg}$ levels measured before I-131 administration.

There have been inconsistent studies to show the prognostic value of early $\mathrm{Tg}$ and delayed Tg in DTC patients prepared with rhTSH. Ciappuccini et al. [23] showed a significant correlation between the rhTSH-stimulated $\mathrm{Tg}$ levels measured immediately before RIT and persistent/ recurrent disease (PRD), defined as evidence of tumor burden confirmed by histology or radiological modalities on follow-up. The early $\mathrm{Tg}$ levels were significantly lower in nonstructural (microscopic) than in structural (macroscopic) residual disease. The reported Tg cut-off value for predicting PRD was $2.8 \mathrm{ng} / \mathrm{mL}$, closed to the threshold defined in our study, with a sensitivity of $86 \%$, specificity of $64 \%$, PPV of $24 \%$, and NPV of $97 \%$. On the other hand, Melo et al. [24] demonstrated that rhTSH-stimulated $\mathrm{Tg}$ measured 3 days after RIT had a predictive value for disease persistence or recurrence 1 year later in 131 consecutive patients. From this study, $\mathrm{Tg}$ levels ranged from 0 to $1927 \mathrm{ng} / \mathrm{mL}$ and were significantly lower in the diseasefree group $(17.9 \pm 49.1$ vs $136.3 \pm 341.0 \mathrm{ng} / \mathrm{mL}$, $p<0.001$ ), with an optimal Tg cut-off level of $7.2 \mathrm{ng} / \mathrm{mL}$.
However, there was no previous report to compare the prognostic value of early $\mathrm{Tg}$ and delayed $\mathrm{Tg}$.

Our study showed that rhTSH-stimulated Tg level just before RIT (early $\mathrm{Tg}$ ) was an independent predictor of excellent response on follow-up, whereas there was no significant difference in Tg levels after RIT (delayed Tg) between the excellent and non-excellent response groups $(5.3 \pm 16.2$ vs $14.9 \pm 36.0, p=0.074)$. Several explanations could be possible. Compared to the study by Melo et al., the proportion of patients with structural incomplete responses among the non-excellent responders were very low in our study ( 80.0 vs $15.4 \%$ ). The Tg levels could also reflect the proportion of structural incomplete responses in a group of patients with non-excellent responses between the two studies. Therefore, the Tg level after RIT (delayed $\mathrm{Tg}$ ) might not have a predictive value for a group of patients with a low proportion of structural incomplete responses, where acute injury effects of $\mathrm{I}-131 \mathrm{on} \mathrm{Tg}$ release could affect the total level of $\mathrm{Tg}$ to evaluate remnant tissue burden.

Giovanella et al. [25] suggested that even Tg measured before TSH stimulation can reflect expression of thyroid remnants by showing a significant relationship between neck radioiodine uptake measured just before ablation and $\mathrm{Tg}$ level measured before rhTSH stimulation and under T4 treatment. Our study showed that $\mathrm{Tg}$ cutoff at $2.0 \mathrm{ng} / \mathrm{mL}$ provided high specificity $(95.3 \%)$ and PPV $(88.2 \%)$ for predicting a non-excellent response, which could be very helpful to decide follow-up strategy based on early $\mathrm{Tg}$. However, the early Tg still has several limitations as predictive factor due to the short TSH stimulation time. In our study, $\mathrm{Tg}$ cutoff at $2.0 \mathrm{ng} / \mathrm{mL}$ provided insufficient sensitivity (46.2\%) and NPV (69.8\%). Tg cut-off value under short TSH stimulation could affect diagnostic accuracy. Our results also indicated that $30.2 \%$ of patients with $\mathrm{Tg}$ levels $\leq 2.0 \mathrm{ng} / \mathrm{mL}$ could not achieve an excellent response. Most of them belong to an indeterminate response group (Table 4), which of 13-20\% are reclassified as having PRD over approximately 10 years of followup [26]. Further investigations are necessary to overcome the physiologic drawbacks of early $\mathrm{Tg}$ as a reliable predictive marker.

Table 4 Early Tg levels and percentages of patient responses to RIT

\begin{tabular}{lllll}
\hline $\begin{array}{l}\text { Early Tg levels } \\
(\mathrm{ng} / \mathrm{mL})\end{array}$ & $\begin{array}{l}\text { Excellent response, } \\
n(\%)\end{array}$ & $\begin{array}{l}\text { Biochemical incomplete } \\
\text { response, } n(\%)\end{array}$ & $\begin{array}{l}\text { Structural incomplete } \\
\text { response, } n(\%)\end{array}$ & $\begin{array}{l}\text { Indeterminate } \\
\text { response, } n(\%)\end{array}$ \\
\hline$\leq 2.0$ & $81(69.8 \%)$ & $1(0.9 \%)$ & $2(1.7 \%)$ & $32(27.6 \%)$ \\
$>2.0$ & $4(11.8 \%)$ & $9(26.5 \%)$ & $8(23.5 \%)$ & $13(38.2 \%)$ \\
\hline
\end{tabular}

$T g$ thyroglobulin, RIT radioiodine therapy 
There are several limitations in our study. First, this study was retrospective, so a selection bias was inevitable. Especially, our protocol for I-131 dose selection has changed over the years based on recent studies and guidelines, which the choice of administered dose was heterogeneous, although there was no significant difference in therapeutic response among I-131 dose like previous studies (Table 2) [5, 6, 19]. Second, delayed Tg was measured $96 \mathrm{~h}$ after the $2 \mathrm{nd}$ injection of rhTSH in some patients due to their admission schedules. However, between the two patient groups undergoing $\mathrm{Tg}$ testing in 72 or $96 \mathrm{~h}$, there was no significant difference in the delayed $\mathrm{Tg}(9.8 \pm 29.7$ vs $8.8 \pm 21.0 \mathrm{ng} / \mathrm{mL}, p=0.832)$ and delayed TSH $\quad(34.1 \pm 27.1 \quad$ vs $28.0 \pm 28.1 \mathrm{mU} / \mathrm{L}$, $p=0.202$ ) levels. Third, although assessment of therapeutic responses was based on the latest ATA guidelines, follow-up protocols were not consistent for all patients. Some patients underwent DxWBS with stimulated $\mathrm{Tg}$, and some patients underwent neck US with suppressed Tg. Further large-scale prospective studies are required to better determine the significance of early $\mathrm{Tg}$.

In conclusion, the early stimulated serum $\mathrm{Tg}$ just before rhTSH-aided RIT significantly predicted therapeutic responses after RIT in patients with DTC. Therefore, physicians should consider measuring the serum Tg level before RIT to predict the therapeutic response, although the early $\mathrm{Tg}$ does not precisely reflect the remnant thyroid tissue burden in DTC patients prepared with rhTSH.

Open Access This article is distributed under the terms of the Creative Commons Attribution 4.0 International License (http://crea tivecommons.org/licenses/by/4.0/), which permits unrestricted use, distribution, and reproduction in any medium, provided you give appropriate credit to the original author(s) and the source, provide a link to the Creative Commons license, and indicate if changes were made.

\section{References}

1. Pacini F. Follow-up of differentiated thyroid cancer. Eur J Nucl Med Mol Imaging. 2002;29:S492-6.

2. Schlumberger MJ. Papillary and follicular thyroid carcinoma. N Engl J Med. 1998;338:297-306.

3. Taïeb D, Sebag F, Cherenko M, Baumstarck-Barrau K, Fortanier C, Farman-Ara B, et al. Quality of life changes and clinical outcomes in thyroid cancer patients undergoing radioiodine remnant ablation (RRA) with recombinant human TSH (rhTSH): a randomized controlled study. Clin Endocrinol (Oxf). 2009;71:115-23.

4. Lee J, Yun MJ, Nam KH, Chung WY, Soh E-Y, Park CS. Quality of life and effectiveness comparisons of thyroxine withdrawal, triiodothyronine withdrawal, and recombinant thyroid-stimulating hormone administration for low-dose radioiodine remnant ablation of differentiated thyroid carcinoma. Thyroid. 2010;20:173-9.

5. Schlumberger M, Catargi B, Borget I, Deandreis D, Zerdoud S, Bridji B, et al. Strategies of radioiodine ablation in patients with low-risk thyroid cancer. N Engl J Med. 2012;366:1663-7.
6. Mallick U, Harmer C, Yap B, Wadsley J, Clarke S, Moss L, et al. Ablation with low-dose radioiodine and thyrotropin alfa in thyroid cancer. N Engl J Med. 2012;366:1674-85.

7. van der Horst-Schrivers AN, Sluiter WJ, Muller Kobold AC, Wolffenbuttel BH, Plukker JT, Bisschop PH, et al. Recombinant TSH stimulated remnant ablation therapy in thyroid cancer: the success rate depends on the definition of ablation success-an observational study. PLoS One. 2015;10:e0120184.

8. Chianelli M, Todino V, Graziano FM, Panunzi C, Pace D, Guglielmi, et al. Low-activity $(2.0 \mathrm{GBq} ; 54 \mathrm{mCi})$ radioiodine post-surgical remnant ablation in thyroid cancer: comparison between hormone withdrawal and use of rhTSH in low-risk patients. Eur J Endocrinol. 2009;160:431-6.

9. Park HJ, Jeong GC, Kwon SY, Min JJ, Bom HS, Park KS, et al. Stimulated serum thyroglobulin level at the time of first dose of radioactive iodine therapy is the most predictive factor for therapeutic failure in patients with papillary thyroid carcinoma. Nucl Med Mol Imaging. 2014;48:255-61.

10. Giovanella L, Ceriani L, Ghelfo A, Keller F. Thyroglobulin assay 4 weeks after thyroidectomy predicts outcome in low-risk papillary thyroid carcinoma. Clin Chem Lab Med. 2005;43:843-7.

11. Kim TY, Kim WB, Kim ES, Ryu JS, Yeo JS, Kim SC, et al. Serum thyroglobulin levels at the time of 131I remnant ablation just after thyroidectomy are useful for early prediction of clinical recurrence in low-risk patients with differentiated thyroid carcinoma. J Clin Endocrinol Metab. 2005;90:1440-5.

12. Webb RC, Howard RS, Stojadinovic A, Gaitonde DY, Wallace MK, Ahmed J, et al. The utility of serum thyroglobulin measurement at the time of remnant ablation for predicting diseasefree status in patients with differentiated thyroid cancer: a metaanalysis involving 3947 patients. J Clin Endocrinol Metab. 2012;97:2754-63.

13. Dow KH, Ferrell BR, Anello C. Quality-of-life changes in patients with thyroid cancer after withdrawal of thyroid hormone therapy. Thyroid. 1997;7:613-9.

14. Pacini F, Ladenson P, Schlumberger M, Driedger A, Luster M, Kloos RT, et al. Radioiodine ablation of thyroid remnants after preparation with recombinant human thyrotropin in differentiated thyroid carcinoma: results of an international, randomized, controlled study. J Clin Endocrinol Metab. 2006;91:926-32.

15. Torres MS, Ramirez L, Simkin PH, Braverman LE, Emerson CH. Effect of various doses of recombinant human thyrotropin on the thyroid radioactive iodine uptake and serum levels of thyroid hormones and thyroglobulin in normal subjects. J Clin Endocrinol Metab. 2001;86:1660-4.

16. Weiss R, Magner J. Serial measurements of serum thyroglobulin in response to recombinant human thyrotropin stimulation. Thyroid. 2015;25:708-10.

17. Taieb D, Lussato D, Guedj E, Roux F, Mundler O. Early sequential changes in serum thyroglobulin after radioiodine ablation for thyroid cancer: possible clinical implications for recombinant human thyrotropin-aided therapy. Thyroid. 2006;16:177-9.

18. Kim YI, Im HJ, Paeng JC, Cheon GJ, Kang KW, Lee DS, et al. Serum thyroglobulin level after radioiodine therapy (Day 3) to predict successful ablation of thyroid remnant in postoperative thyroid cancer. Ann Nucl Med. 2015;29:184-9.

19. Haugen BR, Alexander EK, Bible KC, Doherty GM, Mandel SJ, Nikiforov YE, et al. 2015 American Thyroid Association management guidelines for adult patients with thyroid nodules and differentiated thyroid cancer: The American Thyroid Association guidelines task force on thyroid nodules and differentiated thyroid cancer. Thyroid. 2016;26:1-133.

20. Maldonado G, Greenland S. Simulation study of confounder-selection strategies. Am J Epidemiol. 1993;138:923-36. 
21. Thompson WW, Price C, Goodson B, Shay DK, Benson P, Hinrichsen VL, et al. Early thimerosal exposure and neuropsychological outcomes at 7 to 10 years. $N$ Engl $\mathrm{J}$ Med. 2007;357:1281-92.

22. Bachelot A, Cailleux AF, Klain M, Baudin E, Ricard M, Bellon $\mathrm{N}$, et al. Relationship between tumor burden and serum thyroglobulin level in patients with papillary and follicular thyroid carcinoma. Thyroid. 2002;12:707-11.

23. Ciappuccini R, Hardouin J, Heutte N, Vaur D, Quak E, Rame JP, et al. Stimulated thyroglobulin level at ablation in differentiated thyroid cancer: the impact of treatment preparation modalities and tumor burden. Eur J Endocrinol. 2014;171:247-52.
24. Melo M, Costa G, Ribeiro C, Carrilho F, Martins MJ, da Rocha AG, et al. Stimulated thyroglobulin at recombinant human TSHaided ablation predicts disease-free status one year later. J Clin Endocrinol Metab. 2013;98:4364-72.

25. Giovanella L, Ceriani L, Suriano S, Ghelfo A, Maffioli M. Thyroglobulin measurement before rhTSH-aided 131I ablation in detecting metastases from differentiated thyroid carcinoma. Clin Endocrinol. 2008;69:659-63.

26. Pitoia F, Miyauchi A. 2015 American Thyroid Association Guidelines for thyroid nodules and differentiated thyroid cancer and their implementation in various care settings. Thyroid. 2016;26:319-21. 